\title{
LA LITERATURA CINEMATOGRÁFICA DE MAX AUB: UNA NUEVA PERCEPCIÓN DEL EXTERMINIO
}

\section{Rebeca Gómez Cifuentes}

Investigadora independiente. Filóloga y Doctora en Filosofía, Ciencia y Valores

\section{Resumen}

Max Aub encarna uno de los testimonios concentracionarios más llamativos del s.XX Afiliado a la libertad del hombre, únicamente puede escapar a la desapacible realidad que marcó la era del exterminio refugiándose en el seno de la ficción. La vivencia debe transformarse en experiencia para evitar el memoricidio. Huyó del maniqueísmo haciendo hablar a sus innumerables personajes dándole la última palabra al lector que formará su crónica de la era más aciaga de la Historia. El universo de sus textos sobre los campos se convierte en una perfecta metáfora de la concepción laberíntica que Aub mantenía del ser humano y de la propia existencia y en una demostración de que no es necesaria la escritura autobiográfica para hallar la verdad de una vida. Eso sí, se necesita un nuevo modo de mirar, donde lo mimético, lo diegético y extradiegético se fundan. Una literatura cinematográfica, pues cine y literatura comparten territorio: el de los sueños.

\section{Palabras clave: AUB, MAX (1903-1972); EXTERMINIO; LITERATURA; FIC-} CIÓN; CINE

\section{MAX AUB'S CINEMATOGRAPHIC LITERATURE: A NEW PERCEPTION OF EXTERMINATION}

\section{Abstract}

Max Aub embodies one of the most striking testimonies of the concentration camps of the 20th century. Affiliated with the freedom of man, he can only escape the unpleasant reality that marked the era of extermination by hiding beneath fiction. The life must be transformed into experience to avoid memorization. He fled from manichaeism by making his innumerable characters speak, giving the last word to the reader who will form his chronicle of the most illfated era of History. The universe of his texts on the camps becomes a perfect metaphor of the labyrinthine conception that Aub maintained of the human being and of his own existence and in a demonstration that autobiographical writing is not necessary to find out the truth of life. Obviously, a new way of looking, where the mimetic, the diegetic and the extradiegetic merge is needed. A cinematographic literature, because cinema and literature share territory: the territory of dreams.

Keywords: AUB, MAX (1903-1972); EXTERMINATION; LITERATURE; FICTION; CINEMA

\footnotetext{
Gómez Cifuentes, Rebeca. 2018. "La literatura cinematográfica de Max Aub: Una nueva percepción del exterminio“. AusArt 6(2): 163-179. DOI:10.1387/ausart.20326
}

\section{AUSART}




\section{INTRODUCCIÓN}

El siglo XX ha sido uno de los períodos de la Historia más intensos y convulsos que le ha tocado vivir a la humanidad. Siglo de paradojas y de contrastes, se inició con optimismo, fue testigo del apocalipsis de dos guerras mundiales y terminó con un progreso científico inimaginable que nos condujo a una nueva civilización, que aún no podemos intuir. Nietzsche afirmaba que Europa se había vendido matando bienes tan preciados como la ilusión, la imaginación, el pensamiento o la facultad de generar nuevos ideales. El nuevo modelo de racionalidad moderna está basado en la propiedad y el dominio. La frialdad ante la realidad externa permite al yo ganar estabilidad y reducir las posibles fuentes de sufrimiento y ansiedad, si bien al precio del endurecimiento y la pérdida de flexibilidad. La consigna implícita de este endurecimiento es la estoica indiferencia hacia el dolor propio y ajeno. La frontera entre el bien y el mal se diluye. Sólo de esta manera puede explicarse el estado de excepción propuesto por los regímenes totalitarios, donde lo alegal termina siendo equivalente a lo legal.

Hanna Arendt llega a afirmar que lo más grave, como en el caso de Eichmann, es precisamente que hubo muchos hombres como él, que no eran sádicos ni locos sino tremendamente normales. La banalidad del mal (Arendt 1963) o las zonas grises de Primo Levi son las situaciones que se dan en los campos de concentración donde es complicadísimo establecer responsabilidades, como es el insano deseo de la muerte de un compañero para obtener así una ración mayor de comida, fruto de la más absoluta necesidad. Mantenerse con vida en el espacio letal del campo de concentración no resulta nada fácil y hace brotar del hombre, o de lo que queda de él, las pasiones más bajas. La suerte y la crueldad sin límites son el pasaporte para la supervivencia, 'adaptarse o morir' reza el lema. El campo de concentración ha instituido una nueva forma de muerte, la apoteosis de lo ínfimo, el contacto con la nada. Despoja al individuo de su identidad mediante una serie de mecanismos perfectamente delineados y que hasta provocan en el vilipendiado un sentimiento de culpa y vergüenza que roza lo siniestro. Además de la ruptura moral, el preso asiste a la destrucción de su espacio y de su tiempo. Encerrado, presencia cómo borran su pasado y no dejan opción a su futuro. Se les deshumaniza y se les domina. Las condiciones extremas a las que se les somete, los trabajos forzados y la violencia que soportan los débiles cuerpos propician la ruina del sujeto, la creación del Muselmänner'1. 
Afortunadamente no todo estaba perdido. Olvidaban un dato: es posible matar a los hombres, pero no convertirlos en otra cosa. Por ende, algo en lo más recóndito del ser humano se mantiene con vida y hace del testimonio y de la memoria la base de la recuperación de la arrebatada humanidad y la apertura de un mundo escarmentado por lo anterior y dispuesto a reparar el daño.

La mejor o quizá única manera de testimoniar es mediante la elaboración artística de estos acontecimientos. Afirma Svetlana Alexijevich (2015) que al contar una historia los humanos crean, luchan con el momento como el escultor lucha con el mármol, siendo así, actores y creadores. Ellie Wiesel (1977), sentencia que nuestra generación ha inventado una nueva forma de literatura donde el testimonio deja de ser una declaración enmarcada en un debate, para pasar a ser una institución natural dialógica.

\section{LA LITERATURA ES LA VERDADERA SOLUCIÓN FINAL}

A pesar de vivir una experiencia digna de ser contada podemos no saber reconstruirla de una manera significativa, convertirla en algo comunicable, por lo que es estrictamente necesario el uso del arte para transmitir la esencia (Semprún 2002).

La posibilidad de ser de otro modo es un lujo que supone cualquier vida humana y que debe ser revelada continuamente. Por ello no se buscará realidad única ni preeminente sino se acentuará la diversidad de realidades que el hombre es capaz de abrir, crear y habitar, en las que se conserve la dignidad del ser humano frente a la intención de des-animar del campo. La literatura es donde nuestros anhelos se disuelven ante las formas de ficción que nos regalan determinadas representaciones imaginarias. No olvidemos que el tiempo nos hace entender todo suceso pasado como si fuera una ficción.

El campo de concentración conduce a la transformación del sujeto en objeto. El hombre queda fatalmente confinado en un espacio de absoluta indiscriminación de lo público-privado del cual sólo puede salir mediante el testimonio que al pasar a través de sí mismo como sujeto, supone la clave de la transformación simbólica. Los hechos llegan al lector reconstruidos por la experiencia de los protagonistas y se instalan en la memoria colectiva de la sociedad como 
denuncia de la destrucción ética. Lo realmente importante es hacer historia, no registrar los hechos tal y como ocurrieron realmente. El arte, en este caso la literatura, nos muestra no sólo el Holocausto, sino la consecuencia ética de este reflejada en la conciencia universal. Nuestra relación con el pasado debe ser emotiva: "el pasado tiene que ver con nuestros muertos, y a ellos no los podemos recordar con actitud aséptica, científica" (White 2003, 191).

\section{LA NECESIDAD DE CONTAR}

Como demostró la estética de lo sublime las experiencias ligadas a la muerte, a la supervivencia, al terror, suponen las experiencias más intensas, estéticamente hablando. La destrucción personal es la chispa que ilumina la creación estética, pero en muchas ocasiones, los recuerdos no permiten que el sujeto arme con ellos un texto, de ahí que se recurra a la literatura puesto que la ficción amplía las posibilidades para solventar las carencias de la representación de su experiencia. El superviviente sólo puede apropiarse la vivencia si consigue narrarla, la posibilidad de narrar deriva de la transformación a través del tiempo de la Erlebnis en Erfahrung (Benjamin 1936), de la vivencia en experiencia, transformando a quien lo produce pero también a quien lo escucha y debe ser considerado un instrumento de reconstrucción de identidad. El dato objetivo debe traspasar al lector para alcanzar el 'qualia', de lo contrario se alojará en el cerebro como mera información.

En este tipo de literatura, testimonial para unos, activa o soterrada para otros, lo realmente importante es lo narrado, no el sujeto narrador. Lo plasmado sobre la hoja de papel no es literatura a la manera habitual, sino la acción de asomarse al propio abismo (Müller 2015). De hecho, se plantea que el verdadero testigo, el testigo integral, es el musulmán.

El musulmán ha vivido la experiencia hasta el final, pero no puede testimoniar. Serán los salvados, como los denomina Primo Levi, los que den cuenta al mundo de las atrocidades. Ellos también han de ser testigos de algo que la muerte ha impedido que vivan los hundidos, los derroteros de la vida después del campo. 
Para algunos el hecho de que la literatura medie entre el hombre y sus vivencias le resta fidelidad al resultado, lo que obliga a los escritores a distinguir y explicar la verdad y la verosimilitud en sus escritos. Así, los testigos se sitúan ante la paradoja de tratar de eliminar la subjetividad de su experiencia a pesar de ser esta misma la que dota de validez a sus palabras. La ficción anestesia el sufrimiento para hacerlo más agudo, afirma el propio nombre reivindicando el nombre de los otros, aniquila el mundo para crearlo de nuevo, protege la verdad. A pesar de las diferencias en los escritos de los supervivientes todos ellos desembocan en síntesis similares. Se establece, por tanto, un relato común que se inscribe en la memoria colectiva y lo dota de atemporalidad. El testimonio colabora con el archivo en la construcción del pasado y el planteamiento del futuro. Con su testimonio el escritor nos autoriza a revivir la experiencia transfiriéndonos la propiedad de la misma. Por todo esto, cobra especial importancia la confianza que los lectores depositamos en el interlocutor, lo que no excluye que debamos mantener un criterio selectivo para evitar ser engañados. Cada testimonio va engrosando la memoria colectiva en un periodo de la humanidad en el que se ha producido un cambio semántico respecto al concepto de justicia, término cada vez más acotado. No sólo debemos castigar al culpable sino tratar de reparar el daño causado.

No olvidemos que Auschwitz no fue disuelto por ser Auschwitz sino porque la evolución de la guerra dio un vuelco; y desde Auschwitz no ha ocurrido nada que podamos vivir como una refutación de Auschwitz.

(Kertész 2002)

Pero, una vez decididos a reproducir el mal surge un nuevo obstáculo, el lenguaje no basta para conseguirlo y se deben escudriñar otras técnicas que den el resultado esperado. Con el estallido de las guerras Max Aub, como tantos otros miembros de su generación, adquiere conciencia de que los tiempos reclaman una escritura más ligada a su referente, más transparente ante una realidad que merece ocupar el primer plano de la obra de ficción. Pero, al mismo tiempo, el escritor alberga la convicción de que las nuevas tendencias artísticas, las vanguardias, tienen mucho que decir a la hora de narrar unos acontecimientos con los que, a fin de cuentas, comparten los mismos condicionantes históricos ¿Qué papel puede jugar la razón ante un contexto irracional? Se opta por un realismo vanguardista pluriforme para intentar traducir a palabras una realidad que presenta mil caras, donde el punto de vista del narrador tenga un hueco, pero diluido junto a tantos otros puntos de vista que, 
no por el hecho de ser divergentes, dejan de ocupar un lugar destacado en el mapa moral y amoral de la humanidad del siglo XX.

Aub es consciente de que los documentos pueden mentir, como muestra de ello está el devenir de su propia existencia provocado por una denuncia falsa. Max Aub concibió su literatura como un problema moral, como un ejemplo más de la indignación sentida. La literatura ha evolucionado, no es sólo imitatio sino que crea historias y personajes de los cuales mana verdad y poesía. Crea una ficción y la dota de realidad, de la realidad con la que nosotros como lectores queramos completar el texto. Forja una copiosa variedad de enfoques y repite los acontecimientos según cada perspectiva para que el lector se sienta envuelto en la ilusión de verdad que proyecta. De este modo, con su literatura nos instaura en el principio de empatía pues resulta más fácil identificarnos con un 'otro' que hacerlo con entes abstractos.

\section{AUB, EL HÉROE DE LAS MIL CARAS²}

Max Aub, uno de los escasos testimonios de los campos de concentración del siglo $\mathrm{XX}$, desarrolla una escritura original, experimental y altamente comprometida, sin dejarse tentar por la retórica mitificadora ni por la parálisis creativa que afectó a muchos de sus compañeros. Su gran sentido del humor y de la ironía y su admirable capacidad distanciadora le permitieron cumplir esta tarea de una manera excepcional. Formado literariamente por la vanguardia de los años 20 interpretó el dilema existencial como una licencia para dedicarse a la experimentación, en un intento sistemático por derrumbar los muros entre la ficción y la historiografía. La paradoja propia de la ficción es que si recurre a lo falso lo hace para aumentar su credibilidad. En un contexto irracional no hay lugar para una escritura marcada por la razón.

Tanto para poder dar a sus obras el contenido testimonial que tienen, como para escribir luego en México los cuatro discursos tan abundantes en informaciones precisas sobre el campo de Djelfa, leídos ante la Asamblea contra el poder nazifascista, Aub tuvo que transformarse en observador atento de lo que ocurría a su alrededor y para lo que no pudo presenciar y sin embargo relata, en receptor no menos atento de los testimonios de sus compañeros. 
Aub obliga al espectador a ver el ser del abandono, el campo de la vida desnuda cuya relación se da entre la sospecha, la denuncia y el acecho de la traición. Esto lo relaciona con Giorgio Agamben, pero Aub refleja en sus textos concentracionarios una dimensión que Agamben olvida, la dimensión política de la que nos habla Gustavo Matías Robles (2008). El testimonio no sólo supone una fractura en el sujeto y una imposibilidad de comunicación como él sostiene, sino que también corresponde a un particular modo de la praxis pública: aquel que testifica quiere algo más que referir lo que ha sufrido, quiere también dar cuenta de sus verdugos, quiere hacer una denuncia, señalar un estado de cosas que no debería haber ocurrido y ajusticiarlo, aunque sólo sea simbólicamente, es decir, el testimonio crea una particular manera de posicionarse ante el pasado. Este es el núcleo político del testimonio y sin este modo de confrontación el relato de Aub no podría ser comprendido. Su literatura es un lamento por la traición a los ideales modernos de quien aún cree en ellos. Ni mitificación ingenua ni conciliación insulsa, el gesto político de Aub va en esta construcción incidente que no debe dejar descansar la culpa, mostrando que la humanidad es aquello que debió sobrevivir a su propia vergüenza, a la xenofobia, a la persecución, a la intolerancia, a todo aquello que no debió haber sucedido y que no debe ya olvidarse.

Cuando hablamos de la literatura aubiana, equiparamos los términos posibilidad y ficción y desterramos el uso de la ficción como mentira o falseamiento. El rechazo escrupuloso de todo elemento ficticio no es un criterio de verdad. Muestra de ello es el tan recurrido género non fiction, cuya especificidad se basa en desechar cualquier elemento ficticio, sin embargo, comprobamos que esto no garantiza la verdad. Lo que nos convence de la verdad de la ficción es la sinceridad de los sentimientos expresados. Sería absurdo obviar la falta de veracidad que atesta las obras de autores como Aub, pero debemos tomarla como instrumento que nos conduce irremediablemente a la verdad una vez higienizado el texto. Max Aub no nos miente. En ningún momento nos transfiere su intención de expresar la verdad absoluta, sino que, además, emplea tácticas en las que un lector avezado puede perfectamente descubrir el engaño. De este modo, el lector se transforma en un contrincante intelectual del autor, convocado a descubrir pistas, percibir ironía y autoironía, debatirse entre la verdad y la ficción y, sobre todo, confundirse irremediablemente. Ejemplo de esto es la creación de su personaje Jusep Torres Campalans. No es un personaje borroso, sino que su autobiografía está perfectamente documentada y por ello hubiera sido extremadamente fácil descubrir si existió o no, pero cuando Aub quiso revelar la broma, cuando trató de convencer al público de que se trataba de un personaje ficticio, Campalans ya existía. La precisión de datos y el excepcional conocimiento de los problemas del arte moderno 
mostrado por el autor dieron tal autenticidad a su criatura de ficción, que sólo él mismo pudo desmentir su existencia. De esta forma logra extender la ficción fuera del libro, que es uno de sus grandes aciertos como escritor, ser capaz de que la obra literaria absorba la vida.

Según afirma Francisco Ayala, el problema de la realidad o fantasía que sirve de base a una creación poética es un falso problema. El autor queda ficcionalizado dentro de la estructura imaginaria que él mismo ha producido, aún en el caso de que aparezca en ella ostentando los caracteres de la más comprobable identidad personal.

Aub no trata de reflejar la realidad, y en el momento que descubre un agujero en lo real echa mano del fantasma de la ficción.

Puestos a mentir, hagámoslo de cara; que nadie sepa a qué carta quedarse. Sólo en esta inseguridad crecemos grandes, solos, cara a cara con el otro.

(Aub [1958] 1975, 229)

A lo largo de sus obras nos va realizando preguntas tan llenas de detalles y de alusiones específicas que exigen respuestas emotivas por parte del lector. A pesar de que nos hallamos frente a un genial espejismo narrativo, Aub nos sumerge en la realidad más cruda mediante la presencia de objetos cotidianos o las alusiones explícitas a que estamos siendo víctimas de un engaño. Repite los acontecimientos según cada perspectiva para que el lector se sienta envuelto en la ilusión de verdad que proyecta. Es característico en su obra el desfile de personajes conocidos con una idiosincrasia profundamente detallada para avalar su verdad y dar sensación de vida auténtica. A veces incluso el propio Aub forma parte de la obra o bien descubrimos un alter ego que, en contra de lo que se pueda pensar, no es un fraude, como no lo es la imagen propia que se reproduce en la memoria. Todo personaje proyectado en la memoria por la imaginación o el recuerdo, viene a ser tan real como queremos que sea.

La invención está apoyada en hechos, personajes y fechas de indiscutible autenticidad. La verdad en sus obras tiene la función de convencernos, para que estemos más vulnerables ante la mentira. La mixtificación procede de no poder discenir entre lo inventado y lo acontecido en la realidad fuera de la novela. El problema es ¿con cuánta atención lee uno página tras página tantos datos? 
Sus obras están cargadas de verdades a medias y de toques de humor, a veces gratuito y la mayoría de las veces negro. Una de las técnicas más eficaces que usa para apoyar su invención en una realidad conocida es lo que podríamos llamar el procedimiento de 'dime con quién andas y te diré quién eres'. Escolta a su personaje guía, porque no podemos hablar de protagonistas absolutos, con compañeros o antagonistas que modificarán la realidad según proyecta Aub para esclarecer lo que desea comunicar. Cuando Aub dota a sus personajes de ilustres amigos es motivo de sospecha, por ser un recurso que emplea a menudo para crear esa ilusión de verdad. La abundancia de personajes le permite adoptar divergentes puntos de vista contradictorios, así da rienda suelta a su sensibilidad inherentemente anárquica, lo que Carlos Mainer (citado en García Lora 1973) llama su medular vanguardismo, actitud dadá e irrefenable tendencia al collage. Aub logra embaucar al lector por medio del humor. Si los personajes existen de veras, el tono festivo nos hace dudar. Si son inventados, los detalles personales los hacen parecer verdaderos a pesar del tratamiento humorístico.

Concluiremos este apartado con las palabras de Iván M. Ivanov, uno de los poetas recogidos e inventados por Max Aub en la Antología Traducida de 1972: "No eres lo que te ves en el espejo", y está en lo cierto, porque el espejo refleja una sola imagen y nuestra realidad es múltiple, como lo son las máscaras de Max Aub.

\section{LA ESTÉTICA AUBIANA}

Sánchez Zapatero dice que a pesar de que no fue el único que pasó por los centros de internamiento europeos y africanos, sí fue el único autor de la literatura española para el que la estancia en los campos supuso la génesis de un tópico recurrente de su producción. La mayoría de las narraciones de Aub de la década de los 40 son interpretadas por dicho autor como híbridos entre lo autobiográfico, lo histórico y lo novelesco, y así desgrana sus características: la aludida obsesión por el recuerdo, la polifonía de voces, la heterogeneidad textual, el artificio como forma de expresar lo inefable y la universalidad de la experiencia individual y el valor de quienes mantuvieron firmes sus ideales pese a haber sido condenados por defenderlos. Asistiremos a la superioridad ética de los internados y al categórico desprecio por los responsables de los campos. Puso de relieve su confianza en el ser humano, enfatizó su creen- 
cia en la justicia y remarcó la necesidad de mirar hacia el pasado sin odio ni rencor, a pesar de que el pasado (el yo pasado), en su literatura, se niega a dejarse enterrar (Coetzee \& Kurtz 2015)

Deseó legitimar la literatura como forma de conocimiento y otorgar estatuto de realidad a elementos ficticios, diluyendo así los límites entre ambos. Parece que la única meta debiera ser suministrarles a los lectores una historia que les permita vivir de forma más adecuada. Que les ayude, sobre todo a los que sufrieron los acontecimientos relatados, a sentirse parte de la Historia. La literatura de Max Aub no sólo fue un antídoto para luchar contra la derrota moral que supuso el fracaso militar, sino también el medio con que lidiar la tergiversada historia oficial gestada por el régimen fascista porque la historia estaba contraída bajo la mentira. Aunque hemos llegado tarde a nuestra cita con el otro, debemos al menos salvarlo de la muerte hermenéutica.

Si tomamos como referencia cuatro de las obras de Max Aub escritas en la década de los 40, la novela Campo cerrado, la tragedia San Juan, el poemario Diario de Djelfa y por último la recopilación de ensayos que supone Manuscrito Cuervo podríamos explicar de forma axiomática lo sucedido en el momento histórico en que están inmersas. Así Campo cerrado muestra la necesidad de ser en el mundo. Narra la iniciación a la vida de un joven obligado a luchar para sobrevivir y cómo una vida particular puede ser completamente mediatizada y modificada por el devenir histórico.

Diario de Djelfa supone uno de los pocos testimonios poéticos de los campos del siglo XX. Los poemas surgen como medio para mantenerse atado a la vida, como una construcción racional de la subjetividad. Aub pretende encontrarse a sí mismo, y lo hace reflejándose en los otros, dejando claro que dentro del campo lo importante no es mantenerse vivo, sino mantenerse humano.

San Juan además de mostrar un conflicto histórico, el éxodo de los judíos ante la persecución nazifascista (Souto 1982) y de constituir un valioso testimonio del mismo, puede interpretarse como la metáfora del hombre contemporáneo, a la deriva, víctima de su insolidaridad individual y colectiva. Tras la caída del telón en la oscuridad de un patio de butacas en silencio y acongojado, algo íntimamente humano se extingue con los hundidos.

Manuscrito Cuervo es una obra donde un cuervo que sobrevuela el campo francés de Vernet d'Ariège va trazando un afilado e irónico dibujo de la condición humana desde el discurso neutro propio del zoólogo que examina a una 
especie inferior. Aub parece abominar de ser hombre. El problema no es la ideología política sino que el hombre ha fracasado como tal, como ser social.

Campo cerrado supone la apertura al dolor del alma, dicho dolor aparecerá descarnado en su Diario de Djelfa y quedará personalizado en un grupo de judíos a la deriva en el drama San Juan. Finalmente el laberinto quedará cerrado. El autor reniega del género humano y decide narrar desde la perspectiva enajenada de un cuervo en Manuscrito Cuervo ejemplificando el sinsentido del proyecto totalitario.

Estas obras reflejan que su creatividad fue más allá de la labor de cronista y su desbordante imaginación aportó contribuciones en las que dio rienda suelta a una fantasía extraordinaria. Si el objeto histórico es inaprensible de manera directa y los caminos indirectos, como son los documentos y los testimonios, tienen una veracidad dudosa y una validez cuestionable (...) se ha de entrar en el terreno de la ficción (Sánchez Zapatero 2007).

El autor es el arqueólogo que encuentra ruinas y las hace hablar. Hablar de recuerdos es simplificar demasiado porque podríamos afirmar que lo que poseemos son vestigios de recuerdos que han sido sometidos a una interpretación detrás de la cual hay una determinada voluntad interpretativa.

¿Acaso es posible, filosóficamente pero también neurológicamente, hablar de un recuerdo prístino que no esté teñido por la interpretación?

(Coetzee \& Kurtz 2015)

Se basa, por tanto, en la confianza en la ficción como medio de conocimiento y de forma paradójica, en la interpretación de la memoria como un elemento volátil y fácil de llevar a equívocos. Hace de la suya una de las más interesantes reacciones literarias al sufrimiento de la intolerancia, la barbarie y la marginación. Reivindica la necesidad de inventar y de evocar de forma artificiosa la realidad de los campos para poder transmitir a los lectores el verdadero drama que su existencia supuso.

El autor llegó a afirmar que la realidad es una cosa construible que hay que fabricar. De ahí que sus obras no traten de describir el mundo sino de escribirlo, dejando que se produzca a sí mismo a través de una escritura capaz de aunar el objetivismo y la mirada solidaria, la distancia crítica y la proyección del propio yo. En su literatura, por tanto, hay lugar para la verdad. 


\section{LITERATURA CINEMATOGRÁFICA.}

Estamos en un siglo donde el horror es cierto y contemporáneo. Ante esto, el estilo antiguo se queda corto, insuficiente y Max Aub se ve obligado a crear una forma propia de decir, una manera sorprendentemente rica a la hora de nombrar las cosas, admirablemente bella en los adjetivos y extremadamente moderna en la línea de la más avanzada vanguardia novelística de aquel tiempo y de las nuevas concepciones filosóficas sobre la naturaleza humana.

Son obras de aluvión, de acumulación de escenas que se suceden ante la mirada extática del lector. Tienen estética de reportaje. Al ser tan inmediato el punto de vista, acaba trascendiendo la cronología. Las horas de los hombres que viven la guerra son horas llenas y completas en las que todos los instantes son utilizados y vividos. Las escenas son más cinematográficas que novelescas, apenas hay descripciones de los personajes que hablan y actúan como si estuvieran físicamente presentes, lo que hace superflua toda descripción. Su lucha lleva el germen de un mañana más hermoso, por eso los personajes que nos presentan son sobre todo hombres de palabras que razonan y debaten, que piensan. El diálogo, por tanto, es la columna vertebral de todo el relato. Bien mirado, más que las ideas enunciadas importan las maneras de la enunciación, cómo Max da cuenta mediante determinados recursos literarios de la materia histórica. Es notable la forma que tiene de insertar, casi embutir en el discurso, numerosas citas de extensión variable y cuya procedencia se suele mencionar.

Los tiempos verbales que dominan son el presente y el imperfecto. $Y$ es que el tiempo de Aub es el tiempo vivido, el sentimental. Con ellos subraya la continuidad del tiempo y su permanencia. Se trata de evitar la distinción entre presente, pasado y futuro por ser demasiado racional y no convenir a la concepción de los personajes. No cabe razón en la sinrazón del campo. El tiempo imperfecto es un tiempo inconcluso que tiende a borrar las divisiones temporales de la racionalidad. La discontinuidad de lo narrado en Aub (paso de una historia a otra y de un personaje a otro) confiere a la temporalidad un carácter mortífero y plasma el sinsentido de la existencia.

La guerra se adivina a menudo por el sonido. En las obras asistimos a una pugna de los sonidos unos con otros con la voz humana, que suele estar bregando por hacerse oír en el tumulto de la guerra. No obstante, también hay sonidos artificiales como las sirenas, lo que implica una dimensión lírica que rebasa los límites del lenguaje. También abundan las melodías populares, 
alentadoras y animosas. De esta manera, los personajes se unen en el dolor con sus semejantes.

Al leer nos queda la sensación de que lo narrado está desencadenado, que se siguen múltiples voces como sucede en el cine. Centra su interés en el hombre utilizando el punto de vista como una cámara para mostrarnos los acontecimientos, lo que aporta una gran profundidad pluridimensional. La guerra está vista a ratos de una forma panorámica, a ratos a través del prisma de los personajes. Esto confiere dinamismo a la acción y permite infundir dramatismo a la historia colectiva.

A menudo se le reprochó el carácter fragmentario del hilo narrativo, lo que hace pensar en una acumulación de escenas a menudo sin conexión directa. La elipsis, abundantemente usada, le sirve para recalcar el sentido de lo absurdo ante la guerra.

Es interesante comentar el importante papel que juegan el cromatismo, la luz y los cuadros. El contraste siempre violento entre luz y sombra suele oponer esperanza y desesperación. La principal referencia pictórica es Goya y muchas escenas parecen sacadas de su pincel, además, su estética está también presente en los retratos de los personajes.

Como no puede ser de otra manera, la muerte es el tema omnipresente. Muchos de los personajes miran a la muerte cara a cara, ella es el enemigo que acaba venciéndoles. Hay personajes que saben morir mejor que otros. Son los que encaran la muerte como algo inevitable, lo que hace de ellos héroes de tragedia al enfrentarlos a un poder que rebasa sus fuerzas. A estas muertes individuales se opone otra forma de muerte masiva, la provocada por los bombardeos. Las bombas provocan espanto y deshumanizan la muerte: ya no es un duelo cara a cara sino un castigo ciego venido del cielo al que el hombre no puede enfrentarse. La muerte es una caída física que se acompaña de un derrumbe moral. La vida está más dramatizada que la muerte, impregna cada instante y a menudo se busca como una liberación.

El estilo dialogado y su estructura de guión cinematográfico, las descripciones de paisajes y escenarios concisas, como pinceladas, que tienden a la acotación teatral, el retrato inmediato de cada personaje por muy fugaz que sea su papel y la exposición de la vida del mismo como pequeño cuento en la historia general, la anáfora que evoca un ritmo litúrgico unido al uso abusivo del lenguaje -no es que hallemos vocablos en desuso sino vocablos que jamás se 
han usado-, supone la dicotomía de la literatura Aubiana; es paradójicamente lo mejor y lo peor de ella. Lo mejor por su falta de maniqueísmo y por los razonamientos lógicos y coherentes de los personajes, independientemente de su ideología y lo peor porque ese afán de querer contarlo todo roza el paroxismo.

Max Aub muestra un control absoluto del espacio, muestra acontecimientos producidos en varios lugares al mismo tiempo, lo que concuerda con la forma que tenemos los humanos de captar la realidad. A su vez es portador de una omnisciencia neutra al mostrar un narrador que quiere volverse invisible con el fin de que la historia resulte más impersonal y por lo tanto más objetiva. Por otro lado podríamos decir también, que nos hallamos ante un narrador de omnisciencia multiselectiva. El narrador renuncia a ver la historia desde una posición privilegiada y muestra la perspectiva del personaje, pero al ser tal la multitud de personajes, la información que nos llega a los lectores es casi completa. Es tarea del lector, tras la lectura completa del relato, reordenar los datos y llegar a la historia.

En su literatura el lenguaje es símbolo y no denotación. La complejidad de sus obras reside en lo no dicho y su emisión involucra a un lector-espectador que lo actualice. Lo realmente importante es el compromiso que adquiera el lector tras cerrar el libro.

\section{CONCLUSIONES}

En un tiempo en que el hombre se olvida de lo que es para estimarse por lo que vale, donde la guerra se erige como el estado natural de las relaciones humanas, las obras de Max Aub nacen a modo de exorcismo para contarse y contarnos la tolvanera de sentimientos en la que se halla inmerso. La intención memorialista de Aub nace de un fuerte compromiso con la realidad histórica y de una conciencia artística que consideraba que una obra literaria sólo adquiere su significado completo si es puesta en relación con su marco contextual político, histórico y social. Escribir es una manera de salvaguardar la esencia propia y de no sumirse en la invisibilidad a fuerza de ser invisible para otros. Testimoniar supone una razón que justifica la vida de los que han sobrevivido, supone una ventaja para los lectores de estas vidas y mantiene el recuerdo de aquellos que murieron. La literatura surge como una glosa a la civilización. 
Pero el testimonio del paso de Aub por los campos de concentración y por la Historia no va a efectuarse con un discurso tradicional caracterizado por la identidad entre instancias textuales y extratextuales, sino a través de la configuración de un universo narrativo en el que su experiencia biográfica va a ser ficcionalizada por una suma de voces; se produce en los textos una estructura de narración mise en abyme ${ }^{3}$ en la que una historia se somete a otra. Las diferentes historias individuales van enlazándose a través de diversos y variados modos similares al montaje cinematográfico. Acaban por adoptar una estructura de "vidas cruzadas", todos son protagonistas de sus propias historias, pero al mismo tiempo, son secundarios de las de los demás y del propio contexto en el que están inmersos. Para él la autobiografía abre las puertas a la mentira y a la deformación, mientras que la ficción, cuando nace de la documentación y el cotejo de datos, acoge una interpretación de la realidad poliédrica y compleja en la que tiene cabida tanto lo que fue como lo que pudo haber sido. Más que una mera actitud lúdica, la difusión de los límites de realidad y ficción en la literatura aubiana ha de entenderse como un aviso a los lectores sobre la necesidad de ser críticos y activos ante lo leído.

Aub utiliza la enunciación típica del cine clásico, en sus obras late la esencia de las películas clásicas hollywoodienses de décadas posteriores, que parecen ofrecerse al espectador sin intermediarios. El narrador permanece en ellas voluntariamente oculto, cada personaje tiene su momento y muchas de sus intervenciones dibujan los pensamientos del autor que se graban en nuestra lectura como consignas para la vida. Max Aub se inserta en la ficción transgrediendo los niveles de la narración, disolviendo la distinción creador-criatura, convirtiéndose en simple transmisor de lo hallado, permitiendo al lector ser su propio cronista. En su literatura todo vale porque todo fue.

Como bien la definió Gonzalo Sobejano (1985) se trata de un tipo de literatura que, al tiempo de ser la escritura de una aventura, resulta ser la aventura de una escritura.

A pesar de todo esto, no hay nada nuevo bajo el sol. La abulia acabará apoderándose de todo y absorbiendo sus gritos de libertad hasta, como bien titula Aub una de sus obras, morir por cerrar los ojos. En palabras del propio Aub, nunca se ha visto un país regido por la inteligencia, por este motivo, quizá, autores como él aún no hayan visto la luz demostrando que, como dijo Heine: Allí donde se queman los libros, se acaba por quemar a los hombres. 


\section{Referencias}

Alexijevich, Svetlana. 2015. "Nobel Prize Literature Laureate Lecture", 11 ene. http://www. Nobelprize.org/nobel_prizes/literatura/laureates/2015/alexijevich-lecture_en.html

Arendt, Hanna. (1963) 2003. Eichmann en Jerusalén: Un estudio sobre la banalidad del mal. Traducción de Carlos Ribalta. Argentina: Lumen

Aub, Max. (1940) 1999. Manuscrito cuervo: Historia de Jacobo. Introd, ed. y notas de José Antonio Pérez Bowie; con un epílogo de José María Navarro-Calderón. Segorbe: Fundación Max Aub

- . (1943) 1997. Campo cerrado. Madrid: Alfaguara

- . (1943) 2006. San Juan. Sevilla: Renacimiento

- . (1958) 1975. Jusep Torres Campalans. Madrid: Alianza

— . 1944. Diario de Djelfa. México: Unión Distribuidora de Ediciones

Benjamin, Walter (1936) 2001. "El narrador". En lluminaciones IV: Para una crítica de la violencia y otros ensayos. Madrid: Taurus

Coetzee, John Maxwell \& Arabella Kurtz. 2015. El buen relato: Conversaciones sobre verdad, ficción y la terapia del psicoanálisis. Traducción de Javier Calvo. Barcelona: Penguin Random House

Durán Blázquez, Manuel. 1963. "Max Aub o La vocación de escritor". Papeles de Son Armadans 92: 125-38

García Lora, José. 1973 “Unidad y pluralidad en Max Aub”. Ínsula 13: 320-1

Kertész, Imre. 2002. Yo, otro. Crónica del cambio. Traducción de Adan Kovacsics. Barcelona: Acantilado

Müller, Herta. 2015. En la trampa: Tres ensayos. Traducción del alemán de Isabel García Adánez. Madrid: Siruela

Robles, Gustavo Matías. 2008. "Memoria y testimonio en los escritos concentracionarios de Max Aub" $1^{\circ}$ Congreso Internacional de Literatura y Cultura Española Contemporáneas. La Plata: Universidad Nacional de La Plata

Sánchez Zapatero, Javier. 2007. Max Aub y la escritura de la memoria. Sevilla: Renacimiento

Semprún Maura, Jorge. 2002. La escritura o la vida. Barcelona: Tusquets

Sobejano Esteve, Gonzalo. 1985. "La novela poemática y sus alrededores". Biblioteca Virtual Miguel de Cervantes. www.cervantesvirtual.com

Soldevila Durante, Ignacio. 2003. El compromiso de la imaginación: Vida y obra de Max Aub. Segorbe: Fundación Max Aub

Souto Alabarce, Arturo. 1982. "Letras". En El exilio español en México, 362-409. México DF: Salvat

White, Hayden. 2003. El texto como artefacto literario. Traducción de Verónica Tozzi \& Nicolás Lavagnino. Barcelona: Paidós

Wiesel, Elie. 1977. "The Holocaust as a literary inspiration". En Dimensions of the Holocaust. Evanston IL: Northwestern University 


\section{Notas}

1 'Musulmán': se denominaba así al concentrado que había perdido su espiritualidad, cuya vida había quedado reducida al cuerpo, un cuerpo metonímico. Encorvados hacia delante, como los mahometanos en oración, vagaban solos, con la mirada perdida, sin habla, sin voluntad, despreciados incluso por sus compañeros, porque les recordaba en qué podían convertirse y les mostraba que cualquier atisbo de resistencia o escape, era inútil... Suponían el triunfo del lager.

${ }^{2}$ Calificativo con que lo definió Manuel Durán (1963, 92: 125-38)

${ }^{3}$ Dällenbach, en un trabajo orientado a la especularidad narrativa, divulgaría el término mise en abyme, tomado de la heráldica (el escudo dentro del escudo) aplicado a la ruptura de la lógica formal de los diferentes niveles narrativos y el encajamiento de unos sobre otros.

(Artículo recibido: 31-10-18; aceptado: 07-01-19) 